\title{
An Examination of Some Aspects of Howard Stein's Work
}

\author{
Chris Mitsch
}

\section{Introduction}

Some who read Stein's "Yes, but..." consider his remark that there is "no difference that makes a difference" between realism and instrumentalism a reflection of the paper's most important lesson for those engaged in the debate. Stanford, for instance, focuses on Stein's suggestion that "the dispute between realism and instrumentalism is not well joined," in that there is a convergence of ambitions between a sophisticated realism and a sophisticated instrumentalism [Stanford, 2005, 404-5]. With this lesson in mind, the "no difference" comment seems a natural slogan for the paper's central takeaway.

I don't think the meaning of this slogan is properly understood, however. I will argue that the keys to understanding this remark are not found in the relationships among the various doctrines of realism and instrumentalism per se; rather, the keys are found to be methodological morals that actually preclude the debate. These methodological morals concern the relationship between, on the one hand, philosophy (of science) and science and, on the other, philosophy of science and the history of science. I will show that Stein's view on the contemporary realism-instrumentalism debate (RID) is better seen as a corollary to his views on these other matters than as an isolable verdict. ${ }^{1}$ As such, a proper understanding of his views on the RID must appreciate this broader context. To set this context, I will draw heavily from Stein's dissertation. While it is less clear that they are to form a coherent document, one will find also in his later work considerable support for what I argue here. However, the fact that these are evidently consistent with his dissertation provides support for the idea that his work forms a fairly coherent whole.

The structure of this paper is as follows. In $\S 2.1 \mathrm{I}$ will argue that Stein is wary of the distortions and dangers of undue generalizations, certainty, and clarity in the history and philosophy of science, and that this is alluded to in the opening paragraph of "Yes, but...". Then I will sketch the two methodological morals as they appear in his earlier work: that scientific inquiry is a dialectic $(\S 2.2)$ and that it is an enterprise $(\S 2.3)$. The conclusions that (I suggest)

\footnotetext{
${ }^{1}$ It is at the very least clear that his view of the RID did not change significantly after 1982 when he made reference to the talk that later became the paper [Stein, 1982, 569-70] [Stein, 1987, 391-2].
} 
follow most directly from the former concern what may be called the relation of philosophy (of science) to science, whereas those following most directly from the latter concern the relation of the history of science and the philosophy of science. (Though this structure suggests that the two morals, and perhaps the areas in which the conclusions following from them tend to fall, are more-or-less distinct, I have imposed this structure primarily for readability.) Finally, I will sketch a reading of "Yes, but..." (§3). In $\S 3.1$, I highlight the centrality of the two morals, especially the dialectical conception, to the argument. Then, I show how RID does not respect these morals and is thereby either irrelevant to ( $\$ 3.2)$ or wrong of (§3.3) scientific inquiry. Lastly in $\S 3.4$, and beyond its irrelevance or inaccuracy, I show how these morals suggest that RID is a distraction from a legitimate inquiry that is of relevance to scientific inquiry. I will conclude ( $\S 4$ ) by providing an explanation of Stein's remark that there is "no difference that makes a difference".

\section{Methodological Morals}

\subsection{Explicit reflection on principles: generality, certainty, clarity}

My first observation is, I hope, not contentious: relative to much work in general philosophy of science, the ideas Stein tends to engage with are often not (yet) clear. Perhaps this is just a matter of style, his arguments and conclusions still possessing the usual implicational force. I don't think this is correct, however. My suggestion is this: this is a feature of his work because (§2.1) he is consciously wary of the distortions and dangers of undue generalizations, certainty and clarity, ( $\$ 2.2)$ he strongly disapproves of the rhetorical ends to which these have tended to be put in inquiry itself, and $(\S 2.3)$ likewise disapproves of the ways these have typically been generated from the history. It is, I am suggesting, a reflection of a conscious attention to methodology that is evident throughout his work. In this subsection I will argue that the first part of this suggestion is plausible and is relevant to understanding "Yes, but...".

The title and first paragraph of "Yes, but..." allude especially to his wariness of generalizations:

By the word "skeptical" [in the title, "... Some Skeptical Remarks on Realism and Anti-Realism"] I do not mean to suggest, primarily, disbelief; my ideal skeptic is Socrates, not Pyrrho. Among the claims put forward in recent years in the name of "scientific realism" there are many things I agree with; but there is also an admixture of what seems to me unclear in conception, or unconvincingly argued. This is not so much different from what I thought, in my student days, about the doctrines of logical empiricism - which have since been pretty harshly dealt with. In the latter proceeding, I believe that some rather valuable philosophical lessons have been (at least partly) lost or obscured; and I fear that unless a sufficient ferment of Socratic skepticism is cultured within the realist brew, it will go stale and its vogue too will soon pass. 
I note three things here. First is the nature of his skepticism, which is not to suggest disbelief, he says, but to channel Socrates rather than Pyrrho. This is a common refrain of Stein's. It is important to note here because it tells us the kind of argument we should expect in the following pages. Crucially, the argument is dialectical rather than didactic: it gives his realist/instrumentalist interlocutor space to defend their view, and in so doing Stein aims to expose and scrutinize their goals and presuppositions. This implies that we should take him seriously when he says he agrees with many of the individual claims put forward in the name of "scientific realism" while having serious concerns regarding its conception and arguments in its favor. This means, too, that we should neither expect nor impose a clean categorization of 'scientific realism' or 'instrumentalism'; we as observers are invited to suspend any concern for the RID in favor of learning some "rather valuable philosophical lessons [that] have been (at least partly) lost or obscured." In a sense, we should be prepared for the ground under the feet of the RID to shift.

Second, he points to some of his past thoughts that may serve as a rubric for understanding the argument here. The thoughts here are, he says, similar to those he had of logical empiricism in his student days. Though it is obviously a primary concern of his dissertation, there is curiously little explicit reflection on logical empiricism there. For example, the best we may conclude from the introduction is that, insofar as logical empiricism was to set philosophy on a "safe path" to becoming a science or put it on a "scientific" footing, its failure was evident [Stein, 1958, 2;10]. However, what is present is a (large) collection of particular observations regarding philosophy, science, and their histories. His introduction to the dissertation is dedicated to telling us why his focus is so narrow.

Insofar as his dissertation has a clearly-enunciated aim, it is to determine the "role of philosophy itself in relation to its subject matters," and in particular "its relationship to the sciences" [Stein, 1958, 1-2]. To do this, one could "survey and attempt to systematize" the extant doctrines and then provide a "philosophy of philosophy" that makes cogent the "diversity of philosophic positions on the subject of philosophic diversity." However, the results of such a program are tainted by several doubtful presuppositions. Of major concern is that "[s] uch a program obviously presupposes the greatest possible, that is to say the amplest and also the deepest and most accurate, erudition." Such an approach also presumes that philosophy has an intelligible role (that can be determined by philosophical reflection) and that there is a pattern in the history that will provide insight into the nature of philosophy [Stein, 1958, 3]. There are also two more practical concerns. First, it is clear that "success is contingent upon the adequacy of the sample" [Stein, 1958, 3, fn. 1], which (I suspect) is here even more difficult to guarantee than in more mundane situations. Second, the history of philosophy provides some grounds for skepticism. Regardless of their truth, that so many philosophers "have analyzed and counterbalanced the doctrine of other philosophers in order to educe true principles," is quite persuasive on this point. "That is," he continues, [Stein, 1958, 4] 
the very prevalence in history of essays of the sort contemplated must inevitably tend to the result that another such attempt, even if it succeed [sic], will be likely to experience the fate of those of the past. We have undergone the sophistication of diversity; and any claim, on the part of a philosophy, to be either scientific or encyclopedic, can expect to be entertained with a knowing smile.

This pushes him to find some more modest, promising route of attack. Stein suggests an alternative route to insight "by way of a reflective examination of particular problems" instead of by attempting to provide a systematic philosophy of philosophy [Stein, 1958, 7-8]. This, of course, comes with its own difficulties and dangers:

If one intends to examine problems of the sciences, for instance, one had best be clear as to the stringency of the demands which those particular Muses place upon their votaries; many a distinguished toe has been stubbed for too lightly tripping upon their exigent terrain. So much for difficulty; as for defect, the proceeding is open to the very grave charge, on the philosophical side, that what passes for a plain historical method is rather likely to let principles go by default, or more precisely to move on a ground insufficiently criticized and understood; that is to say, (1) failure to establish first principles first may lead judgment to be based unwittingly upon prejudices; (2) principles inadequately understood may be incorrectly applied, producing merely specious conclusions - conclusions whose contraries may equally be "demonstrated"; (3) an inquiry whose principles are insufficiently established and codified may, even though correctly conducted at each particular stage, lead to changes in the foundation and so to overall inconsistency as it progresses.

For this reason, we must explicitly reflect on what guides our inquiry. Here the sciences suggest some optimism, for they have faced similar difficulties and dangers yet, historically, have at least in part overcome them [Stein, 1958, 10]. We are thus encouraged to study how this is so in the sciences; this Stein does with respect to mechanism from Galileo and Huygens to Schrödinger and Bohr. And as he does consider there to be problems of principle comparable to those of philosophy, some light is shed on the problem in philosophy. But, to reiterate what was stated above, there are few "general" claims made in his dissertation, and the conclusions that are present are sometimes less precise than evocative. Luckily, I am not the only one who thinks so. The closing paragraph of his dissertation alludes to this regarding specifically his final thoughts on Schrödinger's view of human mentality [Stein, 1958, 397]:

The immediately foregoing remarks are extremely disorganized, and it is very hard to attach to some of them any precise meaning. In the latter respect, the problem that they center upon is quite comparable to the problem of the ultimate nature of force as it was discussed 
in the seventeenth century. That discussion was far from fruitless (although the problem was never solved, but ultimately dissolved into far more complicated ones). The point to be made about them is that such remarks ought neither to be dressed up until they can pass for a system of philosophy, nor argued out of existence because of the difficulty of clarifying them: it is philosophical, if not indeed wise, to recognize that in our age as in ages past there are some things that we know; some things that we are more or less clear about not knowing; and some things about which even clarity cannot yet be achieved.

Of course, this does not mean that nothing is clear in Stein or that he believes this is so; he is no obscurantist, nor, I think, does he take himself for one. It does, however, show that he is comfortable with a lack of clarity when no better is possible at the time, and that this has been successful in the history of science; unclarity is an inevitable consequence of seeking wisdom, one that should not be avoided.

Third, and picking back up on the analogy between his thoughts on realism and logical empiricism, the lessons of logical empiricism concern not just the doctrine itself. The crux of the matter is embodied in Stein's later recounting of the discussion following a colloquium presentation of Quine's. Stein was encouraged that Quine and Carnap agreed on the conditions by which their disagreement could be settled, but distressed about the way Quine continued to engage (making it out to be a matter of intelligibility rather than fruitfulness). In fact, Stein seems to side with Quine rather than Carnap on several of the major doctrinal points separating the two. For instance, he tells us: that "we really do not have a satisfactorily analyzed epistemological 'basis' for any department of knowledge, mathematics and logic included" [Stein, 1992, 283]; that the analytic-synthetic distinction "serves little purpose"; and that the observational-theoretical distinction, as Carnap envisioned it, does not work (likewise dooming his inductive logic) [Stein, 1992, 291]. Moreover, it seems clear that moving in the dialectical direction Stein suggests clearly entails a much more idiosyncratic understanding of theory-world relations, one unlikely to be captured adequately by anything so precise as the frameworks Carnap envisioned [Stein, 1992, 292]. This view of Carnapian doctrine is present in Stein's earlier work, too, e.g. [Stein, 1970, 286-7]. There, too, the concern is less about doctrine and more about method; his assessment of the "danger" pointed to is one (he says) Carnap would also agree with, despite Carnap's framework seeming to give rise to it. Like in Stein [1992], Stein is singing the praises of reserve and discrimination:

No attempt to delimit, systematically and globally, the procedures and notions that are empirically legitimate... has really succeeded.To say this... is to deprecate the appeal to programmatic notions as if the program had been realized: this leads to specious criticism... . It has been possible for scientists, in creating, criticizing, modifying, and revolutionizing their theories, to apply what is valid in [principles such as "hypothesis non fingo" and the verifiability theory of 
meaning], despite the lack of an adequate precise general formulation. There is no reason why philosophers of science cannot do the same.

Thus it should be clear that a scholastic salvaging of doctrinal details is not Stein's aim. Rather, what Stein hopes to have persuaded us of - "that there is more in [Carnap's] philosophy than most current representations of it imply" [Stein, 1992, 294] - appears primarily methodological in character. In the end it was Carnap who was the good fallibilist, not Quine: Carnap, he says, was open to wholesale change of his approach to understanding scientific activity (including the doctrine he actually expounded), should it prove not fruitful or representative; Quine, despite his professedly leaving "all open to the flow of experience," obstinately insisted that his current formulation was definitive [Stein, 1992, 292]. ${ }^{2}$ Beyond the obvious thematic similarities with his dissertation (to be noted), this understanding fits well with the few remarks there directed at logical empiricism (above, and one to follow).

On this basis, I hope it will be granted that the first part of my suggestion is plausible: Stein is consciously wary of the distortions and dangers of undue generalizations, certainty and clarity.

\subsection{Genuine skepticism and the dialectic}

In this subsection I will argue that the second part of the above hypothesis is plausible: that Stein strongly disapproves of the rhetorical ends to which undue generalizations, certainty and clarity have historically been put in scientific inquiry. In arguing for this, I will sketch the relationship that he believes has, historically, properly obtained between philosophy and scientific inquiry. This will come down to genuine skepticism, or, what is a right consequence of it, the dialectical nature of science. The clearest examples of his disapproval concern Descartes and the energeticist/phenomenological school of the late nineteenth century (especially Mach). These two cases feature rather prominently throughout his work, including his dissertation. In the latter, each is set up in contrast to another: Descartes to Galileo, and the energeticist/phenomenological school to the atomists.

Take Descartes and Galileo first. As Stein points out, there is a substantial amount of similarity between the two, for "Descartes, like Galileo, knew the laws of inertia; Descartes, like Galileo, knew that the weight of a body produces an acceleration in free fall"; continuing the comparison, "and yet it is Galileo, and

\footnotetext{
${ }^{2}$ This fits well, too, with the following [Stein, 2004, 164]:

a critical mistake has repeatedly been made by philosophers - certainly including natural philosophers. This mistake is the assumption that a clarification of "ideas", or concepts, should always-or can always-precede the advance of knowledge... . More recently, the logical empiricist school-in its early, and still best-known, positions - had the same view; Carnap's later writings show a quite different view of the matter, and this development on his part is what makes me regard him as... a far deeper philosopher than is generally believed.
} 
not Descartes, who is the father of the new mechanics" [Stein, 1958, 58]. A more direct comparison can be made regarding the case of falling bodies, where again they were similarly poised to make an advancement [Stein, 1958, 63-4]. Each began their investigations by (mistakenly) taking the uniformity in the mode of acquisition of increments of velocity to be "in the sense that equal gains of speed are made over equal distances of fall" [Stein, 1958, 64]. Koyré, an earlier interpreter of the relation between them, had therefore concluded (in Stein's words) "that the difficulties into which they fall were due to a common, focal sin against time" [Stein, 1958, 82]. As it turns out, according to Stein, there was a common error across Descartes and earlier Galileo; however, contrary to Koyré, the error Galileo makes in his reductio ad absurdum of the hypothesis that equal gains of velocity are made over equal spaces traversed has a different basis despite being analogous [Stein, 1958, 75-6].

What ultimately interests Stein is the distinction in method. Each began with the same mistake, yet Galileo, and not Descartes, recognized his error and reached the correct conclusion [Stein, 1958, 82-3]. In this way, the case is similar to "the respective roles of Descartes and Galileo in the theory of impact" [Stein, 1958, 83]. One might consider pinning the differential success on Galileo's acceptance, and Descartes rejection, of continuity and of relativitythe "two great principles that dominated fundamental theory in physics from the seventeenth century to Einstein" [Stein, 1958, 85]. But this isn't quite right: "while it is not per se wrong or defective to make what may happen to prove the wrong theoretical commitment, it is defective, it is "unphilosophical" to make any such commitment without adequate reservations or grounds" [Stein, 1958, 85]. It is Descartes's "hubristic" claim of "more than moral certainty" for his principles of philosophy that Stein is reacting to.

Descartes' vice, Stein suggests later, was "a tendency to jump too positively to conclusions, a kind of anxiety about attaining final clarity and certainty" [Stein, 1958, 289]. In contrast, Galileo [Stein, 1958, 87]:

possesses the related merits of reserve and discrimination - the twin virtues of genuine skepticism; one might say, the Platonic virtues of sophrosune and dikaiosune, of balance and judgment.... Above all, he knew the essential difference between the two attributes of a theory, looking good, and being true; and he possessed a fine sense of theoretical relevance. Where Descartes pretended to think out clearly the fundamental principles by which to achieve a rational account of the world, and then by applying those principles to achieve that account, Galileo sought to develop adequate principles in the course of the endeavor to deal with the facts of motion...

Though not always named thusly, these twin virtues of genuine skepticism are ever-present themes in Stein's work (compare also, e.g., [Stein, 1974, 397]).

However, Descartes's is not the only way this anxiety for ultimate clarity and certainty has damaged inquiry. For this reason, the damage is properly said to have been caused by reactions to the anxiety. Where Descartes reacted with hubris, others have reacted with despair: the anxiety "not only can lead to the 
neglect, at great cost, of what though important and fruitful is imperfect, but also can produce as reaction that Pyrrhonism or "skeptical despair" which Kant refers to... as the "euthanasis of pure reason"" [Stein, 1958, 289]. This despair comes in both positive and negative forms. At the outset of the dissertation's body, Stein remarks on an especially strong, and especially negative form. In contrast to Schrödinger - who believes that the "obvious inability of presentday physics and chemistry to account for [the phenomena of life] is no reason at all for doubting that they can be accounted for by those sciences" [Stein, 1958, 11] _ "the philosopher may think that he has better reasons than the mere imperfection of present-day physics and chemistry, for doubting that those sciences can account for the phenomena of life" [Stein, 1958, 12-3]. "But," Stein says, "this is a dubious road; philosophical refutations of the possibility of science accounting for some domain of phenomena have notoriously been the preludes of scientific conquest" [Stein, 1958, 13]. This evaluation of skeptical despair is common throughout Stein's work, e.g., in the more recent [Stein, 2004, 166]:

$I$ think - to make one last appeal to the history of philosophythat the fate of Locke's view that scientific physics is impossible; of Kant's view that scientific chemistry is impossible; of Comte's view that knowledge of the chemistry of the stars is impossible; should all conduce to skepticism about that kind of philosophical skepticism.

Skeptical despair in facing the anxiety is damaging when cast in a positive form, too. This is exemplified in the phenomenalism/positivism at the turn of the twentieth century. What makes this example remarkable

is that the protagonists were not chiefly philosophers, and were not "disillusioned" about the prospects for the advance of science, but were physicists and chemists who espoused with enthusiasm a definite positive program. A second [fact making the example remarkable] is that whereas essentially no contributions to the sciences were in fact made under the aegis of that program, which soon collapsed altogether, the more general philosophical views of its exponents have continued to exert a considerable influence upon the views of both philosophers and scientists to the present day.

The particular case is of the atomic hypothesis. By about 1860, the doctrine of atomic weight was fully established. However, it was still possible "to argue that no convincing evidence at all existed for the hypothesis that matter is composed of discrete ultimate parts" [Stein, 1958, 293]. Indeed, alternate to the atomistic program, there was real reason for the energeticists to hope for a general theory of the modes of energy [Stein, 1958, 295].

However, the energeticists' argument against atoms came not via the evidence but via the perversion of an "economical" manner of speaking. Essentially, they applied different standards to their own and the atomic theory [Stein, 1958, 299]. What had previously been a fruitful positivistic tendency in chemical inquiry was, in the hands of those like Mach, combined "with philosophical 
influences derived from Kant's critique, to produce a school of physical chemists who completely rejected the theory of atoms" [Stein, 1958, 294]. This led to, for one, a specious characterization of atoms as "unobservable" for their inability to be observed in the same way as "everyday" objects [Stein, 1958, 299-300]. What happened was a "subtle transformation" of the metaphysical doctrine of strict positivism, [Stein, 1958, 302]

by which certain theoretical conceptions have their credentials challenged, while it is forgotten that the doctrines in themselves apply quite as well to other conceptions which pass unchallenged; the reality of atoms, for instance, is denied, but the awareness is suppressed that the particular sense of "reality" employed is such that the reality of chairs is equally — or at least comparably —impeachable.

What therefore follows from even a positive skeptical despair is "the tendency to put a stop at a certain stage to the prosecution of theoretical questions by the remark that the aim of science is, after all, just to present the actual facts: description rather than explanation, as the often-quoted dictum of Kirchoff puts it" [Stein, 1958, 303]. ${ }^{3}$

But there is a simple objection to such a perversion of the (otherwise benign) economical manner of speaking [Stein, 1958, 303-4]:

it is an interesting and defensible view that the object of all science is, in some sense, the fullest possible "description" or "representation" of natural phenomena; but then the fact that the theoretical constructions so abstract and so little obvious as the scheme of Newtonian mechanics and its successors have been of such extraordinary power, and capable of such extension and such great precision in the representation of phenomena, deserves more consideration than it tends to be given in the context.

This economical manner of speaking is perfectly acceptable - that is, without an accompanying "subtle transformation." Stein, for instance, is comfortable rephrasing Newton as saying "here is a conceptual scheme involving a certain conception of 'causes' which appears to be eminently useful - even perhaps of ultimate significance - in the elucidation of phenomena" [Stein, 1958, 390]. The manner of speaking simply serves to play up a theory's being a conceptual scheme open to revision or replacement or, equivalently, to minimize readers' "reading in" certainty that is not implied. But this is not the same as what I will call Mach's economical view [Stein, 1958, 390-1]:

\footnotetext{
${ }^{3}$ Mach in particular equivocates on the word 'sensation' to "dispose wholesale of the problems of physics in relation to biology" [Stein, 1958, 302]. He "finally says that it is inappropriate and absurd to seek an explanation of the natural, i.e., physiological process of sensation in terms of the conceptions of mechanics" [Stein, 1958, 303]. But this temptation- "to consider the physiological facts of sensation as simpler and more immediate than the facts of mechanical motion" - might be forestalled by thinking of the physiology of non-human animals [Stein, 1958, 303].
} 
What trouble there is appears to have come from a neglect, by Mach, to consider that the enormous success of Newton's scheme in providing "economical" (and true) representations is itself a fact, not only of history, but about the world: the world is so constituted that the conception, for example, of "internally determined" or natural motions versus "forced" or violent motions leads to a far less economical representation of far fewer natural processes than the conception of "natural powers" as general laws determining the product of mass and acceleration.

So with the economical manner of speaking theories still are about the constitution of the world, whereas with Mach's economical view this has dropped out. Such an economical view of scientific explanation also "led Poincaré to dismiss as idle the question of the true mechanical explanation of electromagnetism" [Stein, 1958, 392].

The lesson here is to maintain a healthy balance of the dual aspects of genuine skepticism - to avoid the trappings of an anxiety for clarity and certainty. This he made clear in his concluding remarks [Stein, 1958, 389]:

There are certain lessons that the history of science seems to teach, and an attempt has been made to adumbrate some of them. But perhaps the most important lesson - and here our examination of history has bordered on moralizing! - is the virtue of a certain combination of enthusiasm for the development and consequential application of systems of concepts, with a kind of caution or ultimate skepticism of the ultimacy of ultimate principles and programs.

What is more, this applies also to conceptions of science itself [Stein, 1958, 389]:

In particular, we have seen twice - in Descartes, and in the energeticist and phenomenologist school of the late nineteenth century - the sort of mischief that can be worked by too rigid an adherence to a creed of ultimate clarity and certainty. And the question arises whether the logical empiricist movement in contemporary philosophy, influenced as it has been by such predecessors as Mach, and committed to a sort of clarity and precision in the language of science, may not be in danger of working the same sort of mischief.

And here we have a more substantial commentary - and further reinforcement of the above interpretation of Stein's remarks - on logical empiricism. In tying it directly to the failures of Descartes and Mach, he makes it clear that the worry for logical empiricism's future is methodological: if its creed is adhered to too rigidly, the same mischief that was worked by Descartes and Mach could be worked by logical empiricism.

Finally, how an individual maintains a healthy balance brings us to the double-facedness, or dialectical nature, of inquiry. ${ }^{4}$ Newton and his contem-

${ }^{4}$ See also, e.g., [Stein, 1990a, 38-9]. 
poraries all appreciated that experience had the final say regarding theories. However, experience should also play a subtler, less well-appreciated role [Stein, $1958,97-8]$ :

In the absence of a general guarantee, the actual execution of the program requires, in Newton's conception, the utmost fidelity to detail in studying natural phenomena. This conception is one of Newton's monumental contributions to science: that in the investigation of natural phenomena details are important, that they may provide the clue to important knowledge and that they must be regarded as a touchstone of truth.

Thus, the role of experience for Newton was "not only that of the supreme arbiter, but also that of the only "official" guide" in inquiry [Stein, 1958, 119]. Many of his contemporaries, and (I add) many since, have failed to appreciate that nature plays this second role $;^{5}$ Huygens and Hooke, for instance, confused inductions from phenomena for hypotheses in arguing against Newton's hypothesis about the constitution of light [Stein, 1958, 98-9] [Stein, a, 15].

In sum, science is dialectical in this thoroughgoing back-and-forth with the world, and it is a proper balancing of the two aspects of genuine skepticism that enables it to function healthily. This requires "the utmost fidelity to details." ${ }^{6}$

\subsection{The "unphilosophical fallacy" and the enterprise}

In this subsection I will argue that Stein also disapproves of the way that undue generalizations, certainty and clarity have been generated from the history of science. Whereas $\S 2.1$ addressed historiography more generally, this subsection will address manifestations of a specific, but common, error among historically-minded philosophers: the "unphilosophical fallacy." It will thereby focus on the second moral: the relation of history of science to philosophy of science. I will begin by probing a passage wherein Stein has paused to reflect on his own historical method. I will then briefly draw out of his dissertation a cluster of claims that appear to be consequences of his historical method.

What Stein notes first is a necessity to distinguish between "questions of historical interpretation - even where such questions involve a component that can appropriately be called "philosophical" - from questions of the philosophy of science per se" [Stein, 1958, 172]. A first-pass understanding might be this: we must distinguish between the philosophy of/in our historical figures and the philosophy of science-as-it-is, which is to say as-we-know-it-to-function. Cognizance of this distinction should, for one, mean we attend especially to actions and reflections of our forebears ways as distinct from a proper and objective understanding of them.

\footnotetext{
${ }^{5}$ According to Stein, this seems to be the significance of Newton's rule IV [Stein, 1958, 98-9].

${ }^{6}$ For more on what this fidelity to detail looked like in astronomy post-Newton, I suggest Smith [2014].
} 
This first-pass understanding is on the right track, for it is, of course, right to distinguish between our own views and interpretive principles and the view of an historical figure. Stein himself makes it clear that he has aimed to understand what the historical figures thought. He says of his theses regarding mechanism, for instance, that "they concern the program in the sense of what was actually done and what was actually intended, for the most part, by its principal exponents" [Stein, 1958, 172]. And one can obviously fail in so distinguishing their own view from their subject's. Failure to do this, Stein suggests, is the reason for Koyré's faulty comparison of Galileo and Descartes. While Stein considered his interpretation of Galileo through the lens of Archimidean Platonism "interesting" and "essentially correct", "his treatment of the historical material, in the light of his interpretive principle [Archimidean Platonism], appears to fall short, to be in a certain sense unphilosophic" [Stein, 1958, 82]:

What Koyré does can be characterized in Platonic terms: he contrives a likely story, but fails of the truth because he has eschewed the more arduous task of a genuine confrontation of reality. That just this is a, perhaps the, characteristic pitfall of philosophy - one might therefore say, "the unphilosophical fallacy" par excellence - is one of the principal theses of the present study; and if the analysis contained in the foregoing excursus is sound, it may serve as a minor example to show that that fallacy, if absolutely inescapable, can at least be relatively avoided.

The distinction, then, means here to rule out "the unphilosophical fallacy" of confusing one's view and interpretive principles with the view of the figure in question.

However, this understanding may still masks two related errors. Recall the distinction between a theory's looking good and being true, introduced in $\$ 3.2$. There, it was emphasized that the air of certainty around 'being true' was merely apparent, and this was demonstrated by introducing as equivalent the "economic" manner of speaking. Here, the air of certainty surrounds 'the philosophy of science per se'. Making the first error, one might take their own philosophy of science to be the ultimate one [Stein, 1958, 172-3]:

There is always a tendency to equate the doctrines of "this our knowing age" with that myth (cf. Huygens's references, on successive pages and clearly intended as equivalent, to "the Philosophy of the present day" and "the true Philosophy"), but this is not a philosophical tendency even though not unknown among philosophers.

The obvious way in which the certainty needs to be stripped is to recognize that we have hardly more right to claim ours is "the true Philosophy" than did Huygens his own. Thus he continues,

To make the distinction cogent, per se must really be attached to philosophy-of-science rather than to science: we must distinguish between what certain men - contemporary or not, scientists or nothave thought about science, and what we think about it. 
The second error is less obvious. Just before his remark on Huygens, Stein tells us that "it is well to bear in mind, in making such a distinction, that "science per se" is a kind of myth, the science with which we are in actual fact acquainted being unavoidably historical." One way in which the science with which we are acquainted is unavoidably historical is just that we write of what has already been produced. But what follows suggests he means something more radical:

But what we think about it [science] is directed to some (historical) "it," and if we think of science as not only a historical product but an enterprise, then what scientists thought about it - what they thought they were doing when they did it - is a significant part of "it" itself.

What appears essential is thinking of science as not only a historical product but an enterprise. Insofar as it is an enterprise the role of its agents must be recognized; hence, our philosophy of science is informed by what was theirs. What this means is that we need not only to recognize that we have no claim to the true philosophy, but that, moreover, because we have no such claim, post-hoc reckonings with scientific theories must attend to what those involved thought. Thus, I suggest that avoidance of the "unphilosophical fallacy" - the "characteristic pitfall of philosophy" - in this context would mean also recognizing science's nature as a flesh-and-blood enterprise, both figuratively and literally. ${ }^{7}$

Committing this fallacy seems to support three distortions that will be relevant in the next section. Though perhaps not so distinct, I will speak of them as if they are for convenience. One such tendency, prevalent with respect to mechanism as elsewhere, has been to view theories as in a sense reified - that is, as (synchronically) stable and epistemically homogeneous collections of principles, results and/or representations regarding a fixed domain of phenomena. However, recognizing the significance of agents when analyzing the history undermines this, at least so far as mechanism is concerned. This program existed in layers, Stein emphasizes [Stein, 1958, 187-8]:

About the higher layers - about the general scheme involving the conceptions of mass and force, of momentum, the conservation of momentum, etc., and indicating the mode in which one ought to attempt to analyze any given natural phenomenon - there was by the last quarter of the seventeenth century a very large measure of agreement... But on the deeper levels there was not only very much

\footnotetext{
7 A note on Stein's uses of 'philosoph-': At least in his dissertation, and I submit it as representative, there appear to be two primary uses. One - often 'philosophy' - tends to be used as a shorthand for the professionalized discipline, and hints of irony are sometimes detected. The second - often an adjectival/adverbial variant, e.g. 'philosophical' — is commonly used in a more genuine classical sense, so that 'philosophical' means something like 'comporting with genuine concern for the growth of knowledge and understanding.'
} 
less agreement, there was also very much more explicit hesitation, and toying with alternatives, on the part of individual thinkers. The mechanistic program was not, even as a program, a finished conception. It pointed, for the investigation of nature, in a certain direction; but it did not completely define a route. It evoked - somewhat variously for investigators imbued with varying philosophic predilections or intellectual dispositions - a certain image of the structure of nature; but it did not clearly exhibit what ought to be the elements of a complete picture of the world.

As a matter of practical consequence, this means that such reification and emphasis of theories papers over not only variation in epistemic commitment but also what is being committed to. Instead, Stein takes the view "of the "ideas" of science (i.e., the most general systematizing principles) as constituting a program rather than a doctrine" [Stein, 1958, 284]; in brief, these programs offer - and are seen by its best prosecutors as offering - regulative rather than constitutive guidance [Stein, 1958, 283].

Another common (and related) distortion concerns the "dynamics" of theory evolution. A famous example, brought to us by Kuhn, is to view the major such changes as wholesale conceptual replacement. This view of theoretical development is, at the very least, not warranted with respect to the mechanistic program. A view of science as a thoroughly progressive development of theories is likewise inadequate. The dynamics is much more complex than either of these views [Stein, 1958, 251]:

... if the development of modern physics from the sixteenth century is viewed as a continuing search for the really basic character of natural processes, then it is possible to see, behind all the revolutions that the subject has undergone, a very direct continuity both of aim and of method; continuity, indeed, in all senses of an ambiguous phrase, in "what the science has been about."...

It is the fashion in these days to refrain from seeing history as a uniform progress toward the one, the true, and the good; and this fashion seems on the whole amply justified. But when the history of physics is viewed in the way we are considering, an exception has to be made of it: there is no denying, as a sheer empirical fact, that the attempt to comprehend phenomena by the Newtonian mechanical program and its successors has been attended with overwhelming, progressive success.

Such subtleties are present also in that "paradigmatic" example of a Kuhnian revolution, namely, the developments at the foundations of physics at the turn of the twentieth century. In that episode there was a kind of continuity as well, preserved through the reinterpretations and redefinitions of central aspects of the mathematical tools at play [Stein, 1958, Ch. VII].

This understanding of program "dynamics" hints at a necessary expansion of what theories can be. The question Stein asks himself with respect to the 
"dynamical" aspect of theories is not whether, e.g., mechanism is being treated as a theory, for "in one sense every program implies a theory; or at least a hypothesis, namely the hypothesis that the program can be successful" [Stein, 1958, 284]. Rather,

The appropriate question, then, is not whether mechanism has in any sense been treated as a theory in this discussion, but whether it has been treated as a theory in an illegitimate sense, that is whether we have supposed susceptible of empirical confirmation a doctrine that is not in fact capable of being either established or overthrown by experience.

The answer is no, for such "doctrine" is capable of being either established or overthrown by experience [Stein, 1958, 288]. Thus, views of the "higher layers" of programs as mere conventions are, if taken too seriously, in danger of misrepresenting the enterprise of science. We will see this mistake soon in Poincaré's philosophy of science.

Whereas the first two distortions involve a kind of reification and homogenization of theories, the third seems to involve not only this but also a homogenization of their relations to the world, as well as a subsequent reification of, as it were, the theory's image of the world. Of course, so far as mechanism is concerned, there is the problem, mentioned above, that it was not a finished conception and therefore did not have a settled "image" of the world. But putting this aside for the moment, Stein, I suggest, is still troubled by such a "crisp" view of theory-world relations. This appears implicit in his discussion of the following characteristic of the mechanistic program [Stein, 1958, 169]:

The test of experience in the narrower sense, the test of any particular explanation (theory) by confrontation with phenomena, was taken in a very stringent way. Not only the general aspects, or certain particular details of the phenomena, but (in principle) all details were expected to be rendered adequately by the theory.

The point I'm concerned with comes in his clarification of the reservation implied by 'in principle'. This clarification comes in three "heads", and the second is most relevant here. It begins [Stein, 1958, 170]:

Second, the theoretical conceptions that are brought to bear in the mechanical explanation of phenomena are not only abstract, in practice their application always involves some oversimplification; and this means that the agreement to be expected between observation and theory is limited by some reasonable estimate of the errors entailed by that simplification. The oversimplifications stem from two causes: lack of detailed information about the actual conditions, and the exigencies of calculation. For example, in discussing the motions of the planets from the viewpoint of the theory of gravitation it is simplest to treat the planets as masses each of which is located at a single point. To a second approximation, the shape of the planets 
may be taken into account by regarding them as spheres. . Next, by taking into account the oblateness of the planets, in particular of the earth, one can deduce a further motion that is in fact observed in the precession of the equinoxes.

What I see as latent in this observation is that such knowing oversimplifications complicate the ways theories "represent" the world, their diversity implying, in turn, a diversity of ways of "representing." This is clear in realizing that our "reasonable estimate of the errors entailed" by an oversimplification, which inform our expectations for agreement between observation and theory, is itself informed by our understanding of the role that simplification plays in the situation. For this reason, assuming theories represent the world in largely homogenous ways - or, in more explicitly enterprise-y terms, that scientists believe that their theories are this way; believe that they come with something like a basic, general set of rules for how to apply them ${ }^{8}$ - is not appropriate.

Thus in this way, too, assuming a theory implies a crisp world-according-totheory "image" is unwarranted. What this means in practice is that a scientist's "belief" in a theory needn't engender strict reductionist dismissal of other researches by dint of their not conforming with its "ontology". And at least so far as mechanism is concerned, it didn't. That is, [Stein, 1958, 172]

the "reduction" of phenomena to "mechanical causes," as that envisaged in the mechanistic program, does not entail the concentration of scientific interest upon phenomena of motion, to the neglect of the intrinsic qualities and patterns of things. Fresnel's mechanical theory of light, for example, is not primarily a theory of the jostlings and tuggings of particles of ether, but of such qualitatively optical phenomena as the formation of images, double refraction, patterns of color and shade produced in diffraction, and so forth.

So however it was that mechanists envisioned the world through the eyes of the program, it was not so psychologically domineering as to suppress more "ontologically" nebulous inquiries.

\section{3. "Yes, but...": a dialectical undoing of the RID}

In the last section I argued for three main points. First (§2.1), I argued that Stein is consciously wary of the distortions and dangers of undue generalizations, certainty and clarity. To establish this, I showed that the opening remarks of "Yes, but..." allude to and thematically mirror those that framed his dissertation, wherein this fact is apparent. Second ( $\$ 2.2)$, I argued that Stein disapproves of the rhetorical ends to which such undue generalizations, certainty and clarity have been put in inquiry itself. Ultimately, this came to

\footnotetext{
8 "In short," Stein says, "[Newton's program] is not a program that works automatically" [Stein, 1958, 96-7]. See Chapter V, especially pages 96-100.
} 
his appreciation that science is a dialectic, hence his turning away from the anxiety for ultimate clarity and certainty and his championing of Newton's genuine skepticism in the study of natural phenomena. Third (§2.3), I argued that Stein disapproves of the ways such undue generalizations, certainty and clarity have been generated from the history. This was evinced by his reckoning with the subtle and pervasive consequences of "the unphilosophical fallacy," or what is the same, his affording of respect to the many layers of complexities of the flesh-and-blood enterprise of science. I will now bring these observations to bear on "Yes, but...".

The structure of Stein's argument in "Yes, but..." can be confusing read linearly. For this reason, what follows is not a line-by-line or paragraph-byparagraph reading. Instead, in light of the $\S 2$ discussion, I will present it as a kind of "dialectical undoing": I will describe Stein's reckonings with the presuppositions and misconceptions that underpin the RID in the order of (my estimation of) their importance. My aim in this is to better emphasize how the dialectical conception of science and the unphilosophical fallacy guide the three major motifs of the argument in "Yes, but...". Each of these will be given their own subsection. The concluding subsection will consist of a brief characterization of what Stein takes to follow from the three major motifs.

\subsection{The dialectic of science}

The first motif of the argument in "Yes, but..." actually pushes us toward Stein's own dialectical view. This view is already doing heavy lifting by the second page. By then, he has already ruled out trite instrumentalism and expanded the scope of a sopisticated instrumentalism to include all of "the world of experience." This immediately rules out any (even epistemically "principled") instrumentalism that tries to delineate what can be (or is) known of the world from what cannot be (or is not) [Stein, 1989, 56]. Thus, in Kantian terms, we are already empirical realists. Like in his discussion of Mach, we are ruling out any laying of constitutive principles and thereby rejecting the faulty-empiricist double standard. Stein therefore assumes that the instrumentalist's claim can be read as: "A theory is "nothing but" an instrument for representing phenomena" [Stein, 1989, 50].

Stein characterizes this as a "somewhat liberalized instrumentalism." Whether or not Stein really thought this was only somewhat liberalized, this is clearly not true: what Stein in fact describes is a maximally liberalized instrumentalism, being "instrumentalism" only in the sense that it is presented in the economic manner of speaking. When Stein later elaborates on the first irony of the RID's treatment of this history by considering the case of Poincaré, this is clear [Stein, 1989, 56]:

The contested reality was of the ether; and Poincaré, because he regarded the ether as a fiction rather than a reality, was unwilling to take very seriously (although he was willing to play with) the idea that charged particles exchange momentum with the ether. This, however, is a very odd position for an instrumentalist to take (the 
first irony); for there is no warrant at all in the instrumentalist view for grading the entities of a theory in degrees of reality or fictitiousness - regarding particles as more real than the ether.

Like the energeticists and Mach, Poincaré had "subtly transformed" the economic manner of speaking into what I've called the economic view. He did this by speciously distinguishing between charged particles and the ether, despite their being equally real by his own standard [Stein, b, 21-2]; Poincaré had effectively endorsed the double standard Stein sees as recurring in the empiricist tradition (e.g., in Locke [Stein, 1990a, 33-4], Hume [Stein, 1990b, 209;219][Stein, 1993, 189-90], Mach (above)). ${ }^{9}$

The sophisticated "instrumentalism" in play throughout "Yes, but..." is therefore only a different manner of speaking. All it serves to do is emphasize that our knowledge and understanding are still subject to expansion and revision. So when Stein remarks that the empiricist double standard is "a bit of unregenerate realism, doing the work of the Devil among the empiricists and instrumentalists" [Stein, 1989, 56], he is not alluding to the realist and instrumentalist doctrines familiar from the RID; rather, he is saying the following: the misguided empiricist has (i) succumbed to the tendency to speak in a realist manner in the cases that are "closer to home" and an economic one elsewhere (perhaps because of some anxiety for ultimate clarity and certainty), but (ii) failed to recognize that these are, at bottom, just manners of speaking, and therefore (iii) mistaken the linguistic shift for something real. This he sums up in closing [Stein, 1989, 64-5]:

What we are left with is that other, provisionally, "ultimate" or unexplained fact, that we $d o$ find ourselves compelled to formulate our beliefs in non-phenomenalistic terms; and in this process, atoms, electrons, fields, and the like are in a case quite analogous to that of chairs, tables, and the like in Berkeley. The justifiable claim to "reality" possessed by [sic] those "theoretical entities" is of the same kind as the justifiable claim - not after all denied by Berkeley - of these ordinary objects. To hold this is to reject the faulty-empiricist double standard; and "realism" in this sense I endorse unreservedly.

\section{2. "Nothing but" and "something more"}

The second motif concerns the instrumentalist's claim that theories are "nothing but" instruments and the realist's that theories are "moreover" true. However, because Stein has rejected the faulty-empiricist double standard, the "instrumentalism" of which he speaks is rather anti-realism. This is to say that

\footnotetext{
${ }^{9}$ Luckily Einstein, unlike Poincaré, took the theory seriously as a guide to how the world is and explored its implications [Stein, b, 23]. Lorentz, too, took the theory seriously [Stein, 1987, 389-90] by recognizing the same distinction as did Maxwell between "what is known with some security, or held at least with some probability, and what is bare and even implausible conjecture" [Stein, 1989, 62].
} 
Stein's dialectic view suggests that the RID is, in its purest form, the transcendental debate between realism and anti-realism (e.g., idealism). ${ }^{10}$ The question being debated is thus whether the noumena are anything like the phenomena. Berkeley, for one, was an anti-realist. His doctrine was "that what is real is just minds and their perceptions, and that all our beliefs about the physical world are just "instruments" for organizing and anticipating experience" [Stein, 1989, 61]. Stein asks of this doctrine: can it be refuted? Need it be refuted?

One might think that, since a phenomenalistic basis does not appear possible, Berkeley is after all wrong: it cannot be that all of our beliefs - especially our belief in such a world - are but instruments. But this does not get at (what Stein believes is) Berkeley's essential point, which is that there is an insuperable gap between the world and our experience of it. As we may view Kant as doing, the failure of phenomenalism could just be considered a fact about us rather than the world as it is independently of us. How could you possibly respond to an anti-realist like Berkeley? If even the failure of phenomenalism is irrelevant, it seems nothing we know - in the everyday sense of the word - would satisfy the anti-realist. Need one, then, reply to the anti-realist? No, Stein says - they are "irrelevant to any real issue in the understanding of science" [Stein, 1989, 65]; there is no need to reply to the anti-realism of, e.g., Berkeley, Kant, or later Putnam.

Some have risen to the anti-realist's challenge, however. This is the case, for instance, with Boyd's proposal for determining "real" validity over "mere" instrumental validity - the latter meaning that a theory affords a correct and adequate representation of phenomena. Boyd and his anti-realist interlocutor have both assumed this instrumental validity from the outset Boyd $[1983]^{11}$. The question Boyd then tackles is thus understood as: how do we determine whether theories are "moreover" true of the noumenal realm? Boyd claims that evidence that theories are "moreoever" true comes from considering "the connection of theories with the ongoing process of scientific inquiry" [Stein, 1989, 51]. However, because Boyd's claim is at best an hypothesis - it in principle could not have been "induced by the [noumena]," for we have no access to that realm - it cannot explain; his purported explanation is "disconnected from its explanandum" (see: color location problem, Huygens [Stein, 1989, 53-5]). This is in contrast to Huygens's hypothesis regarding the constitution of light: that hypothesis led rather directly to further investigations of optical phenomena, and in this sense was a good hypothesis according to Stein. For Boyd's claim to likewise be a good hypothesis, it would need to lead to unmediated investigations of the noumenal realm as it really is. However, this is not possible by definition, so it can lead to no further inquiry. This is Stein's point (a): "argument to a better, or the best, explanation is a doubtful business, which

\footnotetext{
${ }^{10}$ It is seemingly for this reason that when Stein later refers to this paper, he calls it "an article devoted entirely to the issue of realism and anti-realism" [Stein, b, 22].

${ }^{11}$ Boyd's publication concurrent with "Yes, but...", Boyd [1989], also fits the description here.
} 
I should prefer to view as abductive, or heuristic, or tentative at best; and in the present case, I do not see what investigations are to follow the abduction" [Stein, 1989, 52]. Understood in this way, as a debate about transcendental semantics, Boyd's claim - like the anti-realist's - is irrelevant to understanding science.

But the situation is even worse than this, for the terms of the debate seem to rule out the identification of any non-transcendental "something more". This Stein summarizes in his point (b), that he does not believe that the explanation does in fact explain [Stein, 1989, 52-3]. For suppose that Boyd's hypothesis does actually explain something about scientific theorizing and is thus evidence for the realist thesis. What is this thesis? It is that theories that are correct and adequate representations of phenomena "moreover" possess some extra attribute; i.e., we're putting aside those attributes had by correct and adequate theories, each of which presumably concern the theories, the phenomena, or relations thereof. By (a) we know that whatever this extra attribute is, it cannot concern relations to the noumena. But then this extra attribute must somehow concern either the phenomena, the theory, or relations thereof. However, whatever it is, this attribute would fail to be "something more" - it would be precisely one of those attributes put aside in the search for something more. Therefore, because the realist thesis fails to identify any (non-transcendental) extra attribute which is to be explained, we surely cannot identify evidence that does explain it. So either, as in the last paragraph, the realist thesis takes the noumenal sense, which means that it cannot be explained and is irrelevant to science; or we assume that Boyd's hypothesis explains, in which case it can't be explaining the realist's "moreover" thesis. Should the realist forego this "something more," they are left with no way to distinguish themselves from the dialectical and enterprising inquirer, whose explanation of theorizing they insist is inadequate.

It is in this temptation to respond to the anti-realist that the taste for genuine explanations is lost, and the arguments slide into, e.g., claiming that things would be miraculous otherwise. But an enthusiasm to find out need not, and in especially the best scientists does not, give way to such an anxiety in the face of "inexplicable" facts [Stein, 1989, 64]:

Indeed, if one examines the explanation offered by science today for the existence and properties of aluminum..., it is hard not to feel that this explanation, at least as much as Berkeley's, grounds ordinary things upon a miracle; but the simple fact is that whatever our science adopts, perhaps provisionally, as its "ultimate" principles, just because they have no further ground, remain "inexplicable"; and the farther they are from the familiar, the more they will seem "miraculous".

In this sense, miracles are a natural part of the dialectic of science.

This loss of the taste for genuine explanation is made palatable by the Quinean motif of the "ontology" of theories [Stein, 1989, 57]. This is because the motif does little to dispel the misconceptions noted in $\S 3.3$. Here it is relevant that the focus on "ontology" has tended to bring with it a view 
wherein theories induce (by a privileged semantics) a "crisply" reified image of the world. This leads naturally to a comparison problem: is the actual world -independent of our theorizing, and as represented with this privileged semantics - (approximately) the same as the theory's image of it? The realists and anti-realists then look to the history to support their contrasting claims.

But this is to commit "the unphilosophical fallacy" in the several ways of the last section. Among the misconceptions that seem to get this comparison problem off the ground is the assumption that theories always imply precise characterizations of the world. This is evident, for instance, in the debate of Putnam [1975] and Laudan [1981] regarding the reference of 'atom' and 'ether'. Each is assuming that a "proper" analysis of the theories in question will reveal that 'atom' and 'ether' each correspond to precisely-characterized aspects of reality that we now know to, respectively, be and not be present. However, this assumption is problematic. For one, each aspect in fact does appear present in substantial ways and, moreover, according to the same metric of "presentness" (i.e., being weighable). More generally though, our understanding of what is "implied" by the theories has been subtlized, demonstrating that even "fixed" theories don't imply fixed, sharp images of the world.

This points to a broader sense in which the unphilosophical fallacy has been committed here. What underlies the assumption that theories imply precise characterizations of the world is the privileging of a robust semantics of theoryworld relations. The central notion for Putnam and Laudan, for instance, is reference. However, the notion does not play for them the same role it does in the Tarskian semantics from which it appears borrowed. ${ }^{12}$ Consider the term 'ether' as it occurred in the nineteenth- and twentieth-century theories (for the moment, let's assume these "theories" make distinct existence claims about the ether). Recall the T-schema: '...' is true iff ...* ", where ' '...' is a metalanguage name for a claim in the object language and '..${ }^{*}$ ' is the metalinguistic translation of that claim. Let's consider, as a claim made by the nineteenth-century theory, the statement 'Light travels through an ether'. The T-sentence for this claim as made in the context of the nineteenth-century theory is then:

'Light travels through an ether' is true iff light travels through an ether*

We are presuming that this statement was taken as true then, hence the latter is satisfied. Then, the T-sentence for the claim as made in the context of the twentieth-century theory is:

'Light travels through an ether' is true iff light travels through an ether**

\footnotetext{
${ }^{12}$ See Maddy [2007], especially Part II, for a similar and more careful treatment of truth and reference in scientific inquiry. Like Maddy, Stein appears to consider Tarski a disquotationalist [Stein, 1989, 50].
} 
We are presuming that the claim is false, hence the latter is not satisfied. However, to say with Putnam and Laudan that the former is true while the latter is false, what has actually changed is the metalinguistic translation (noted with (**'), and therefore the base clauses in the metalanguage's definition of truth. This is precisely to note that 'light travels through an ether' is not a statement that is true or false simpliciter. Baked into this change is a fluidity of the notion of reference at play: the notion of reference one distills changes along with the change of metalanguage, and for this reason it takes a backseat to translation in Tarski. ${ }^{13}$ In this sense reference and truth are trivialized in Tarskian semantics: they are (sometimes useful) linguistic devices meant to capture obvious and basic features of linguistic use. The machinery doesn't tell us anything substantial about either how we do or ought to determine whether a statement is satisfied or how we do or ought to perform translations. What it actually seems to do is draw our focus to the changes in knowledge and understanding that inform these decisions.

There is essentially only one way for Putnam and Laudan to "untrivialize" reference and truth, though it comes in different forms. One form fixes the notion of reference and insists that translation and truth must run through it. This, in turn, means that there is an objective and precise fact about the referential relations enjoyed by a statement. One can then say that 'Light travels through an ether' was considered true by nineteenth-century theorists but was, in fact, objectively false; since the statement's referential relations do not change, there is no meaningful change of the metalanguage. A second form insists that there is an objective fact regarding the preservation of meaning by translation. What this boils down to is assuming there is one meta-metalanguage in which all equivalences across metalanguages can be judged: i.e., the meta-metalanguage allows us to form statements like [Light travels through an ether*]+ iff [Light travels through an ether**]+ that express the equivalence of metalinguistic translations of an object-language statement. This essentially allows us to express in the meta-metalanguage that the nineteenth-century theorist's metalanguage is not one that appropriately translates their object-language statement, so that they misunderstood the genuine meaning of their statement and thereby considered it true when it was, in fact, false.

These moves are essentially the same, however, in that each treats the semantics as beyond reproach, i.e. outside the dialectic. In the former form, the nineteenth-century theorist either held the wrong metalanguage or held the right one and misunderstood it; in the latter form, they either held the wrong meta-metalanguage or held the right one and misunderstood it. ${ }^{14}$ But in either case, it is assumed that we've reached the ultimate, not-subject-to-revision lan-

\footnotetext{
${ }^{13}$ For instance, the new metalanguage need not even translate the statement compositionally or in the same compositional manner, the former of which simply eliminates any meaningful role for reference.

${ }^{14}$ The errors could, of course, have been in still-higher languages, but I ignore these cases because the main point is unchanged.
} 
guage in which we can evaluate "objectively." 15 Though it manifests differently, the effect is of a kind with the faulty-empiricist double standard: an end is put to inquiry. Insofar as this is considered a philosophy, it is also to commit the unphilosophical fallacy in the same way as Huygens: assuming one's own is the True philosophy, not subject to modification and thus treated as outside of the dialectic of science. The problem is thus not reference per se but assuming that there is a once-and-for-all way to capture word-world relations. ${ }^{16}$ Because such assumptions lie "outside" the dialectic, this is to go "external" in the Carnapian sense. ${ }^{17}$

\subsection{Excessive simplicity}

The third motif is an attempt to take the debate as an honest empirical inquiry into the historical use of theories, despite this not being the aim of Boyd or Laudan. However, the outcome is still negative. Even taken in dialectical stride, reference as a robust concept is clearly too simplistic to represent theoryworld relations. What these relations actually look like is better captured by what Stein calls 'theoretical structure'. However, one should take care not to read too much into 'theoretical structure'; what is meant is loose, something along the lines of 'conceptual system'. This is intimated in his nodding to Hilbert et al. (see Stein [1988]). For them, the goal was Tieferlegung der Fundamente, which I prefer to translate as 'foundational deepening' to more strongly emphasize its ongoing nature. Even at their most pristine, which is to say as a system of axioms, theories were constantly subject to modification, axioms being added, subtracted, modified, or even removed to elevate "mere" theorems. This was done according as our understanding of the world and the conceptual system itself changed. Hilbert, for one, considered this foundational fluidity in his axiomatic approach "a tremendous advantage", for it makes room for conceptual and interpretational play while still allowing one to preserve what is considered essential mathematical/conceptual components in the process (for

\footnotetext{
${ }^{15}$ There is a certain methodological irony here, too: in assuming a True philosophy so as to provide an objective description of past theorizing, one plays down what can more fairly be called objective - descriptions of what the past scientists thought they were doing. Presumably, only the former description is open to revision via scientific developments after these past scientists' time.

${ }^{16}$ The assumption can be especially pernicious, as it has been in discussions of color as a Lockean quality: what was once taken to be a clear and justly-answerable question about the nature of things - what quality of bodies does color resemble? - should, by dint of subsequent research, be seen as fundamentally confused [Stein, 1989, 53-4]. (In fact, research done prior to Locke's publication of the Essay showed this Stein [2004].)

${ }^{17}$ Recall that Stein has a quite liberalized notion of linguistic framework in mind. He is also acutely aware of the "mutual dependence of frameworks and theories," and therefore the danger that "the internal/external distinction may lead to the neglect of important large questions that span the development of theories" [Stein, 1970, 285-7]. Thus, the internal/external distinction here is just between dialectical and non-dialectical inquiry. This use of the distinction appears to be one of the "valuable philosophical lessons" of logical empiricism, alongside the illuminating discussions of its flaws.
} 
instance, see Frege's excerpt of Hilbert's 29.12.1899 [Frege et al., 1980, 41]). ${ }^{18}$

Indeed, in pointing to quantum mechanics as one of his concrete examples, the ever-changing and idiosyncratic nature of how theories represent is a prominent part of Stein's conclusions [Stein, 1989, 59]:

I do not claim to have a definitive formulation of the meta-physics of quantum mechanics; but I believe rather strongly that the difficulties it presents arise from the fact that the mode in which this theory "represents" phenomena is a radically novel one. In other words, I think the live problems concern the relation of the Forms - indeed, if you like, of the Instrument- to phenomena...

In addition to its suggesting that quantum mechanics represents phenomena in a novel way, this remark suggests that theories prior to it had "represented" in different modes, too. In equating 'Forms' with 'Instrument'- which we know to be the acceptable economic manner of speaking of theories - it is underscored that Stein's notion of structure is intentionally nonspecific, riding on his nonspecific characterization of theories.

Such uses of reference, as in the case of atoms and the ether, moreover reveal a misconception of theories as stable and homogeneous sets of beliefs such that we can specify their every representational feature. They are believed stable in the sense that what is and is not "in" the theory is clear. This is leveraged for claims like "nineteenth-century electromagnetism implied the existence of an ether' to appear sensible, when it is, in fact, often difficult to draw the line between a theory and its interpretation. ${ }^{19}$ They are moreover assumed homogeneous in that their hypotheses and demonstrations are treated as on an epistemological par. This gives rise to statements like 'mechanism assumed all aspects of the world are explainable ultimately in terms of particles'. But this assumes both an agreement on high-level mechanistic conceptions as well as a strong reductionism which did not exist generally among its practitioners.

Correcting these misconceptions of theories as stable and homogeneous also corrects assumptions about how theories evolve and what they are for. When it is claimed, for instance, that 'ether' was believed to refer but was later discovered not to, this is taken to reveal a fairly discrete change in theoretical commitments. Subtleties of what was actually shown aside, this appears to assume that theoretical advancement is straightforwardly represented with something like a network of propositions: nodes as beliefs, edges as inferential connections, and when those beliefs that "impinge" on experience are overturned, we strive

\footnotetext{
${ }^{18}$ To get a better feel for what I mean by conceptual/interpretational play see Weatherall [2018], where it seems even profoundly formal approaches to understanding theories (in the context of equivalence, in particular) inevitably involve extra-formal judgments of theoryworld relations; the formalism doesn't just "spit out" an interpretation. This should be still more obvious with theories axiomatized $\grave{a}$ la Hilbert or with those not presently susceptible to even this approach, the latter of which appear to be most common.

${ }^{19}$ Thus it was that Hertz's famous remark that "the Maxwell theory is the system of Maxwell's equations" was actually a reflection of a deep scientific achievement. See Stein [1970, 281-2].
} 
to "mutilate" as little of the network as possible in accommodating the change. But this assumes a lot. Not least, it assumes that all the important features of scientific inquiry are appropriately captured by looking at propositional and fundamentally representational claims about how the world is. However, important features arise also from intimations concerning aspects of this knowledge itself, including not only the pedigree of the individual nodes but of the connections among them. In at least this sense, science is not only an enterprise of knowledge but also of understanding Stein [2004]. Thus, when Boyd calls attention to "the connections of theories with the ongoing process of scientific inquiry" [Stein, 1989, 51], Stein sees this as a call to attend to these extra- or merely heuristically-representational aspects of theories - what may broadly be called methodological, as opposed to metaphysical aspects.

Theories are therefore for more than representing, and as a consequence their merely representational aspects must be considered in that broader context. In particular, it would appear ill-advised to play one off the other in the way some RID arguments have tended to. Laudan, on one hand, focuses on the representational aspect of theories, taking their historical alternations to tell us that theories are "mere" instruments; Boyd, on the other, appears to focus predominately on their methodological aspect, taking the historical continuity to tell us that theories are "moreover" true. The RID thereby tends to generate from the history "conclusions whose contraries may equally be "demonstrated"" [Stein, 1958, 9] because of an inadequate understanding of the principles guiding the debate. Both the "wanton" and "teleological" interpretations of the history have some truth to them; however, as a point of historical fact, neither adequately characterizes any substantial swathe of inquiry on its own. Lost in the back-and-forth are the varied ends to which theories have been put by science's agents: Resources for inquiry - Yes, but...representational-Yes, also.

\subsection{No difference that makes a difference}

Finally, where does the argument of "Yes, but..." leave us with regards to an understanding of scientific inquiry? The emphasis just placed on science's agents in understanding theories suggests one direction: taking seriously what they think about science and what they think they're doing when they do it. In so doing, it also suggests still more concerning the "wanton" and "teleological" views of inquiry. Not only are they and their presumed opposition-as well as their hidden philosophical and historiographical premises - inadequate as a matter of historical fact, they are moreover of dubious worth even as guides to further inquiry. We recognize this, Stein's work seems to suggest, when our focus is returned to inquirers themselves. This focus is evident in what is arguably the central thread of Stein's philosophy: if and how individual inquirers can claim to know anything when they can believe nothing certainly.

As I hope to have shown in $\S 2$, Stein was already heartily pulling this thread in his dissertation. There, the thread culminated in the following question [Stein, 1958, 392]:

Is the degree of dispassionateness in ultimate formulation, which in 
the view here presented philosophy seems to require, compatible with the degree of passionate conviction required for a scientist like Newton, or Maxwell, or Einstein, to devote himself to the development of his "daring hypotheses" in the teeth even of great opposition?

As we've come to expect, he answers this question by appealing to an example he considers representative. Funny enough, the example will be familiar to readers of "Yes, but..." - for it is precisely the one he gives to clarify and make plausible his "no difference that makes a difference" claim: Maxwell's systematic removal of his ether model from the theory of electromagnetism. Unlike in "Yes, but...", however, he there makes explicit what answer this example is to give. What this answer is should, by now, come as no surprise: "Here the history of science is rather encouraging to the old view of man as capable of rationality" [Stein, 1958, 392-3].

I wish to recommend we take seriously Stein's belief that it is possible to reconcile these two aspects of genuine skepticism as a call for inquiry into how this is so; I suspect this is what he intended, too. ${ }^{20}$ In taking this inquiry seriously, I think it is appropriate to see this as a development of the RID into a related question that is both relevant to scientific inquiry (and thereby, philosophy of science) and more ripe for attack than it was 30 years ago. ${ }^{21}$. This is no small undertaking; it is likely to span not only the specific sciences themselves, but much of the cognitive and psychological sciences, such as perception and attention, concept formation and structure, learning and expertise, motivation, biases and constructivity, the structure and functions of memory, developmental, social, and educational psychology, and aspects of psychology still unconceived or unrecognized. ${ }^{22}$ Naturally involved will be a careful attention to how various aspects of cognition, including mathematics, are embodied, have evolved, and are culturally shaped. To put things in Stein's own words, the broader question is this [Stein, 1989, 55-6]:

... how [is it] that our own natural endowment - which has evolved for its "instrumental" value in coping with far more immediate aspects of the world - has also proved to be an "instrument" capable,

\footnotetext{
${ }^{20}$ For one, Nancy Nersessian's doctoral dissertation was titled Scientific Evolutions: On Changing Conceptual Structures in Science, and her research since has taken a robustly interdisciplinary approach to this cluster of issues. She completed her dissertation with Stein [Nersessian, 1977].

${ }^{21} \mathrm{I}$ am borrowing from Stein the phrase and conception of question-changing in the growth of understanding and knowledge [Stein, 2004, 165].

${ }^{22}$ These issues are highly complex and interrelated, too, necessitating extreme care when considering "big pictures" of the role our endowment plays in how inquiry works. To give one example demonstrating (the possibility of!) a kind of upward percolation of conceptual revision in cognitive research: recent results [Winter et al., 2016] from the centroid paradigm [Sun et al., 2016] suggest the potential incompleteness of the feature integration theory [Treisman and Gelade, 1980], the latter of which influences our understanding of the binding problem as well as Getalt principles. Changes in our understanding of the latter could rather quickly force modifications to any "big picture" of the nature of knowledge (as evidenced in, e.g., [Spelke et al., 1998]).
} 
under favorable circumstances, of (e.g.) discovering quantum mechanics[?]

\section{Conclusion}

In closing, I would like to return to that fated remark - that what Stein really believes "is that between a cogent and enlightened "realism" and a sophisticated "instrumentalism" there is no significant difference - no difference that makes a difference" [Stein, 1989, 61]. On its face, as Stanford intimates, the claim appears to be about two views per se: upon finessing, the views themselves converge such that they are no longer distinct. Understood this way, it would seem that the RID is still "well-joined" in the sense that its broadest ambitions are clear and well-founded but that (i) the realist and instrumentalist views so far proffered in the RID are wrong, and (ii) the correct view is something of a blend of the two.

This isn't quite right. As the scare quotes seem to indicate, we aren't dealing with views at all, let alone views proffered in the context of the RID. On the one hand, a sophisticated "instrumentalism" recognizes that theories are for representing in addition to being resources or "instruments" for inquiry; it has been "sophisticated" in that it has traded in the anti-realist's philosophical skepticism for the genuine skeptic's reserve. Having done so, the error of the faulty empiricist double-standard is apparent, and thus returns the capacity for genuine discrimination by fidelity to detail. On the other hand, a cogent and enlightened "realism" recognizes that theories are resources or "instruments" for inquiry in addition to being for representing; it is "cogent" and "enlightened" in that it has traded in the transcendental philosopher's pseudo-answers - explanations disconnected from their explanandum - for the genuine skeptic's discrimination by fidelity to detail. Having done so, the error of the faulty realist's claim to the True philosophy is apparent, and thus returns a genuine reserve. With the hubris of the RID realist and the despair of the RID instrumentalist removed, there is no clear debate left: the genuine skeptic makes quick dialectical work of the oversimplifications born in the realist and instrumentalist of the "unphilosophical fallacy", and with these goes, too, the judiciousness of realism versus instrumentalism.

What is therefore left are two manners of speaking: a "realism" whereby one speaks passionately of what the world is and isn't like, so far as we know, and an "instrumentalism" whereby one speaks dispassionately of the forms of our current theories while still taking them seriously as about the world. To speak in either manner is to strive to live in accordance with the twin virtues of genuine skepticism - to practice balance and judgment. That these different manners of speaking - passionately with Maxwell as a "realist" or dispassionately with Lorentz as an "instrumentalist" - make no difference in the practice of our best scientists, as the history suggests, is then an empirical fact about us in our relation to the world. So for at least as long as it remains cogent to say that these manners of speaking differ while making no difference, we should seek to understand how this is so. 
P. Kyle Stanford. Instrumentalism. In The Philosophy of Science, pages 400400. Psychology Press, 2005.

Howard Stein. On the present state of the philosophy of quantum mathematics. In PSA 1982, pages 563-581, 1982. vol. 2.

Howard Stein. After the baltimore lectures: Some philosophical remarks on the subsequent development of physics. In Robert Kargon and Peter Achinstein, editors, Kelvin's Baltimore Lectures and Modern Theoretical Physics, pages 375-398. MIT Press, 1987.

Howard Stein. An Examination of Some Aspects of Natural Science. PhD thesis, University of Chicago, 1958. University of California: Microfilm.

Howard Stein. Was carnap entirely wrong, after all? Synthese, pages 275-295, 1992.

Howard Stein. On the notion of field in newton, maxwell, and beyond. In Roger B. Stuewer, editor, Historical and Philosophical Perspectives of Science, pages 264-287. Minnesota Studies in the Philosophy of Science, vol. V; University of Minnesota Press, 1970.

Howard Stein. The enterprise of understanding and the enterprise of knowledgefor isaac levi's seventieth birthday. Synthese, 140:135-176, 2004.

Howard Stein. Maurice clavelin on galileo's natural philosophy. British Journal for the Philosophy of Science, 25:375-397, 1974.

Howard Stein. On locke, 'the great huygenius, and the incomparable mr. newton'. In Phillop Bricker and R.I.G. Hughes, editors, Philosophical Perspectives on Newtonian Science, pages 17-47. MIT Press, 1990a.

Howard Stein. Newton: Philosophy of inquiry and metaphysics of nature. Unpublished manuscript, a.

George Smith. Closing the loop: Testing newtonian gravity, then and now. In Newton and Empiricism, pages 31-70. Oxford University Press, 2014.

Howard Stein. Yes, but...: Some skeptical reflections on realism and anti-realism. Dialectica, 43:47-65, 1989.

Howard Stein. Physics and philosophy meet: the strange case of poincaré. Unpublished manuscript, b.

Howard Stein. 'from the phenomena of motions to the forces of nature': Hypothesis or deduction? In PSA 1990, pages 209-222, 1990b. vol. 2.

Howard Stein. On philosophy and natural philosophy in the seventeenth century. Midwest Studies in Philosophy, 18:177-201, 1993. 
Richard Boyd. On the current status of the issue of scientific realism. Erkenntnis, 19(1-3):45-90, 1983.

Richard Boyd. What realism implies and what it does not. Dialectica, 43(1-2): 5-29, 1989.

Hilary Putnam. Philosophical Papers: Mathematics, Matter and Method, volume 1. Cambridge University Press, 1975.

Larry Laudan. A confutation of convergent realism. Philosophy of Science, 48 (1):19-49, 1981.

Penelope Maddy. Second Philosophy: A Naturalistic Method. Oxford University Press, 2007.

Howard Stein. Logos, logic, and logistiké: Some philosophical remarks on the nineteenth century transformation of mathematics. In History and philosophy of modern mathematics, volume 11, pages 238-259. Minnesota studies in the philosophy of science: Minnesota University Press, 1988.

Gottlob Frege, Gottfried Gabriel, Brian McGuinness, and Hans Kaal. Philosophical and mathematical correspondence. Oxford: Basil Blackwell, 1980.

J. O. Weatherall. Theoretical Equivalence in Physics. ArXiv e-prints, October 2018.

Nancy Nersessian. Scientific evolutions: On changing conceptual structures in science. Ann Arbor, Michigan: University Microfilms. Howard Stein and Raymond J. Nelson, supervisors., 1977.

A.N. Winter, C. Wright, C. Chubb, and G. Sperling. Conjunctive targets are hard in visual search but easy in centroid judgments. Journal of Vision, 16 (12):750-750, 2016.

P. Sun, C. Chubb, C.E. Wright, and G. Sperling. The centroid paradigm: Quantifying feature-based attention. Attention, Perception, and Psychophysics, 78 (2):474-515, 2016.

A. Treisman and G. Gelade. A feature-integration theory of attention. Cognitive Psychology, 12(1):97-136, 1980.

ES Spelke, E Newport, and R Lerner. Nativism, empiricism, and the development of knowledge. Handbook of child psychology, 5th ed., Vol. 1: Theoretical models of human development, pages 275-340, 1998. 